\title{
Original
}

\section{Characterization of Microsatellite Markers Covering Chromosome 1 in the Korean and Japanese Population}

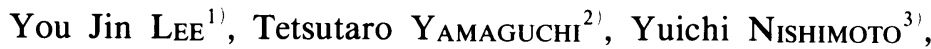 \\ Soo Byung $\mathbf{P}_{\mathrm{ARK}}{ }^{1}$, Akira MIYAZAKI ${ }^{3}$ and Koutaro $\mathbf{M}_{\mathrm{AKI}}{ }^{2}$
}

\begin{abstract}
Microsatellite markers are useful markers for genetic linkage analysis. However, it has been demonstrated that ethnicity plays a significant role in genetic variation. To investigate genetic variation between the Korean and Japanese populations, 51 microsatellite marker loci spanning the entire human chromosome 1 were acquired from a commercially available set (ABI PRISM Linkage Mapping Set-HD5). The allelic frequencies and heterozygosities for these marker loci in 96 unrelated Korean subjects and 96 unrelated Japanese subjects were determined. Of the 51 markers tested, significant differences were observed when the microsatellite allele frequency pattern of Koreans was compared with those of the Caucasian model, whereas the pattern was highly similar between the Korean and Japanese populations. Our data indicate that an extensive verification of public microsatellite markers in a particular population, especially in Koreans, should be undertaken prior to linkage studies. Moreover, our findings should facilitate genetic linkage studies of various hereditary diseases.
\end{abstract}

Key words : allele frequency, heterozygosity, microsatellite markers, chromosome 1

\section{Introduction}

Microsatellites are an essential tool for genetic linkage analyses. They are selected in genetic studies on the basis of both their value in terms of information and their positions with respect to one another on the genetic map. Genetic mapping locates one gene locus relative to another, the position of which is known by the frequency of recombination for Mendelian traits, or the concordance or discordance of affected sib pairs for polygenic traits. Microsatellites markers are identified using a suitable computer program. These markers then have to be tested for their uniqueness and suitability in linkage analyses studies. They are assessed according to the level of heterozygote frequency of the microsatellite alleles as well as the relative allele frequency. Because microsatellites are distributed prolifically throughout the genome and are highly variable in repeat length and in polymorphisms, they have become powerful tools for genetic mapping of disease susceptibility loci.

\footnotetext{
1) Department of Orthodontics, College of Dentistry, Pusan National University, 1-10, Ami-dong, Seo-gu, Pusan 602739, Korea.

${ }^{2}$ Department of Orthodontics, Showa University School of Dentistry.

${ }^{3)}$ Department of Biochemistry, Showa University School of Medicine.
} 
Several screening sets of microsatellite markers have been described in the literature ${ }^{1-4)}$, and such marker sets designed for genome-wide screening have recently become available commercially. Most of these marker sets have been prepared according to information obtained from the Caucasian population, as their allelic frequencies are more readily available. Yet significant differences were observed when the SNP allele frequency pattern of Koreans was compared with that of Caucasians and Africans ${ }^{5)}$. Differences in both the allelic frequency and the heterozygosity of many microsatellite markers between Caucasians and Japanese have also been found ${ }^{6}$.

In the present study, we compared the allelic frequencies and heterozygosities between Korean and Japanese populations for all of the 51 microsatellite markers spanning human chromosome 1, which contains over 3000 genes and over 240 million base pairs, of which $\sim 90 \%$ have been determined.

\section{Subjects and Methods}

Genomic DNA was isolated from 96 unrelated Korean subjects and 96 unrelated Japanese subjects, from both whole blood using a QIAamp DNA Blood Kit (QIAGEN GmbH, Hilden, Germany) and from buccal cells using a BuccalAmp DNA Extraction Kit (Epicentre Technologies, madison, WI, USA). An ABI PRISM Linkage Mapping Set-HD5 (Applied Biosystems, Foster City, CA, USA) containing fluorescent labeled primer pairs for 51 microsatellite markers was used for genotyping. Polymerase chain reaction (PCR) amplification of each DNA segment of interest was performed in 96-well plates in a volume of $6 \mu$ l, containing $5 \mathrm{ng}$ of genomic DNA, $0.2 \mathrm{mM}$ dNTPs, $1.5 \mathrm{mM} \mathrm{MgCl}_{2}, 0.6 \mu \mathrm{l} 10 \times \mathrm{PCR}$ buffer, 2 pmol of each primer, and $0.15 \mathrm{U}$ AmpliTaq Gold (Applied Biosystems). After a pre-PCR heating step for $12 \mathrm{~min}$ at $95^{\circ} \mathrm{C}, 35$ cycles of amplification $\left(15 \mathrm{~s}\right.$ at $94^{\circ} \mathrm{C}$ for denaturing, $15 \mathrm{~s}$ at $55^{\circ} \mathrm{C}$ for annealing, and $30 \mathrm{~s}$ at $72^{\circ} \mathrm{C}$ for extension) were performed in GeneAmp 9700 thermal cyclers (Applied Biosystems). The PCR products were combined into pools, analyzed on ABI 377 DNA sequencers, and genotyped using GeneScan (version 3.1) and Genotyper (version 2.5) software (Appiled Biosystems). Caucasian-derived genotypic data (heterozygosity) for each marker was obtained from the Genome Database (GDB; http://www.gdb.org) and from an online source (http://research.marshfieldclinic. org/genetics/). The Ethical Committee of Pusan National University and Showa University approved this study, and all subjects gave their written informed consent.

\section{Results}

Among the 51 microsatellite markers in the original set (ABI PRISM Linkage Mapping Set HD-5), heterozygosity was different in a significant fraction of the markers between Koreans, Japanese and Caucasians (Table 1). Differences in heterozygosity of over 0.2 between Koreans and Caucasians were found in 5 markers $(9.8 \%)$, and between Korean and Japanese in only 1 marker $(2.0 \%)$ (Fig. 1 ). The mean heterozygosity of the markers was 0.67 (Korean: range 0.23-0.91, Japanese: range 0.29-0.92). In addition, four Korean markers $(7.8 \%)$ and three Japanese markers $(5.9 \%)$ were found to show heterozygosities lower than 0.6 (Table 2). Of the markers examined, $5.9 \%$ of the Korean group and $3.9 \%$ in the Japanese population showed heterozygosities below 0.5 , which is insufficient for linkage analysis. This low level of usefulness was not found for any of the Caucasian markers. 
Table 1. Distribution of heterozygosities of microsatellite markers in the original ABI PRISM Linkage Mapping Set HD-5

\begin{tabular}{cccc}
\hline \multirow{2}{*}{ Heterozygosity } & \multicolumn{3}{c}{ Frequency $(\%)$} \\
\cline { 2 - 4 } & Korean & Japanese & Caucasians \\
\hline$<0.5$ & 5.9 & 3.9 & 0.0 \\
$0.5-0.6$ & 2.0 & 2.0 & 0.5 \\
$0.6-0.7$ & 52.9 & 47.1 & 8.7 \\
$0.7-0.8$ & 31.4 & 21.6 & 38.0 \\
$>0.8$ & 7.8 & 25.4 & 52.8 \\
\hline$>0.6$ & 92.1 & 94.1 & 99.5 \\
\hline
\end{tabular}

Ethnic differences of Heterozygosities

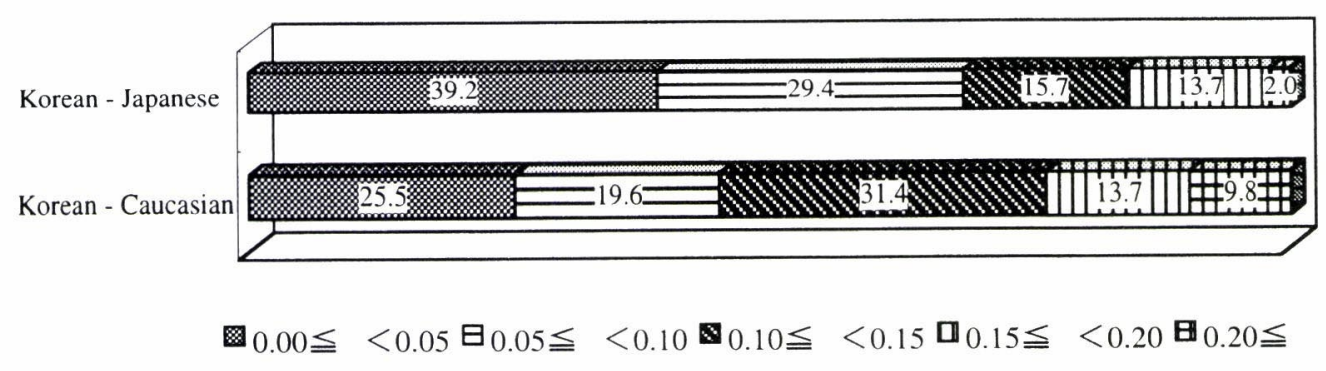

Fig. 1. Ethnic differences of heterozygosities of microsatellite markers between the different populations

\section{Discussion}

Genetic variation has been used for the identification of disease-related genes. Among those genetic variations, SNPs and microsatellites are the most common source of variation between individuals, detected at a frequency of approximately 3000 or more in the human genome. Therefore, microsatellites could be of value for genetic mapping studies, which may lead to a better understanding of the genetic basis for complex diseases. They are therefore considered as promising markers for genetic linkage analysis. This study examined the distribution of 51 microsatellite markers at intervals of approximately $5 \mathrm{cM}$ of allele frequency amongst the Korean and Japanese populations.

Although significant differences in microsatellite allele frequency were detected among the different ethnic groups, the comparison of allele frequencies between Koreans and Japanese showed a high similarity of microsatellite allele frequency patterns. Genetically, Koreans are nearest to Mongolians and are related to the Japanese. This lends genetic evidence to the ethnohistoric account of the origin of Koreans from Central Asia ${ }^{7}$, and most authors agree that Koreans are from a North Asian population group ${ }^{8)}$. Japanese and Korean populations may share some common genetic structure that could reflect recent gene flow and some amount of admixture of $\mathrm{Y}$ chromosomes between these two populations ${ }^{9}$. These results may also support the "out of northeast-Asia hypothesis" concerning the origin of the 
Table 2. Heterozygosities of tested markers

\begin{tabular}{|c|c|c|c|c|}
\hline \multirow{2}{*}{ Locus } & \multirow{2}{*}{$\mathrm{cM}$} & \multicolumn{3}{|c|}{ Heterozygosity } \\
\hline & & Korean & Japanese & Caucasians \\
\hline D1S468 & 4.22 & 0.71 & 0.69 & 0.75 \\
\hline D1S2660 & 10.78 & $0.34^{*}$ & $0.52^{*}$ & 0.78 \\
\hline D1S214 & 14.04 & 0.76 & 0.72 & 0.80 \\
\hline D1S450 & 20.61 & 0.68 & 0.80 & 0.81 \\
\hline D1S2667 & 24.68 & 0.71 & 0.83 & 0.82 \\
\hline D1S434 & 29.93 & 0.61 & 0.61 & 0.61 \\
\hline D1S507 & 33.75 & 0.65 & 0.81 & 0.78 \\
\hline D1S2644 & 43.72 & 0.68 & 0.64 & 0.81 \\
\hline D1S199 & 45.33 & 0.77 & 0.69 & 0.84 \\
\hline D1S2864 & 50.28 & 0.77 & 0.83 & 0.80 \\
\hline D1S234 & 55.10 & 0.71 & 0.77 & 0.82 \\
\hline D1S2892 & 70.41 & 0.91 & 0.73 & 0.89 \\
\hline D1S2713 & 73.81 & $0.23^{*}$ & $0.37^{*}$ & 0.75 \\
\hline D1S2797 & 75.66 & 0.76 & 0.73 & 0.73 \\
\hline D1S2652 & 80.77 & 0.61 & 0.67 & 0.64 \\
\hline D1S2700 & 87.31 & 0.79 & 0.85 & 0.89 \\
\hline D1S2846 & 91.89 & 0.64 & 0.65 & 0.56 \\
\hline D1S230 & 95.31 & 0.65 & 0.63 & 0.79 \\
\hline D1S198 & 99.30 & 0.80 & 0.78 & 0.80 \\
\hline D1S2841 & 106.45 & 0.85 & 0.77 & 0.78 \\
\hline D1S500 & 107.56 & 0.72 & 0.62 & 0.64 \\
\hline D1S207 & 113.69 & 0.74 & 0.79 & 0.84 \\
\hline D1S2868 & 126.16 & 0.64 & 0.61 & 0.77 \\
\hline D1S206 & 134.20 & 0.68 & 0.81 & 0.82 \\
\hline D1S495 & 136.88 & 0.61 & 0.62 & 0.87 \\
\hline D1S2726 & 144.38 & 0.62 & 0.67 & 0.75 \\
\hline D1S252 & 150.27 & 0.64 & 0.83 & 0.82 \\
\hline D1S498 & 155.89 & 0.77 & 0.73 & 0.82 \\
\hline D1S2635 & 165.62 & 0.65 & 0.72 & 0.86 \\
\hline D1S484 & 169.68 & 0.62 & 0.68 & 0.64 \\
\hline D1S2878 & 177.86 & 0.76 & 0.82 & 0.84 \\
\hline D1S196 & 181.49 & 0.61 & 0.66 & 0.73 \\
\hline D1S218 & 191.52 & 0.73 & 0.84 & 0.83 \\
\hline D1S2818 & 198.30 & 0.62 & 0.65 & 0.70 \\
\hline D1S238 & 202.73 & 0.82 & 0.81 & 0.86 \\
\hline D1S2877 & 205.40 & 0.61 & 0.63 & 0.72 \\
\hline D1S413 & 212.44 & 0.70 & 0.64 & 0.77 \\
\hline D1S249 & 220.65 & 0.69 & 0.64 & 0.87 \\
\hline D1S245 & 227.81 & 0.64 & 0.62 & 0.83 \\
\hline D1S425 & 231.11 & 0.65 & 0.62 & 0.81 \\
\hline D1S227 & 238.52 & 0.61 & 0.72 & 0.71 \\
\hline D1S213 & 242.34 & 0.69 & 0.81 & 0.86 \\
\hline D1S2833 & 245.05 & $0.59^{*}$ & 0.61 & 0.83 \\
\hline D1S2709 & 247.23 & 0.67 & 0.89 & 0.73 \\
\hline D1S2800 & 252.12 & 0.73 & 0.67 & 0.79 \\
\hline D1S2850 & 256.26 & 0.61 & 0.63 & 0.65 \\
\hline D1S2785 & 266.27 & 0.73 & 0.92 & 0.77 \\
\hline D1S304 & 267.51 & 0.62 & 0.61 & 0.61 \\
\hline D1S2842 & 273.46 & 0.64 & 0.68 & 0.78 \\
\hline D1S423 & 277.80 & $0.44^{*}$ & $0.29^{*}$ & 0.61 \\
\hline D1S2836 & 285.75 & 0.61 & 0.79 & 0.78 \\
\hline
\end{tabular}

* microsatellite markers with heterozygosities of below 0.60 
Japanese population ${ }^{10}$. Recently, it was reported that the Asian population has the smallest number of distinct SNP haplotypes. Furthermore, allele frequencies between Korean and Japanese populations are comparable with previous data for the Japanese population only " , suggesting a common origin of ancestry, as expected from the close geographical location of the two countries ${ }^{5}$.

Ikari et $a l^{12}$ reported that the microsatellite markers (ABI PRISM Linkage Mapping Set-MD10) established among approximately $10 \mathrm{cM}$ were tested in 64 unrelated Japanese individuals. Thirty of these markers were included in our investigation, and our findings on the heterozygosity for these markers supports this previous work.

Our study has one important limitation, in that the ethnic differences in allele frequencies between Koreans and Japanese are based on a relatively small sample size. Since genotype distribution with small sample sizes is sometimes different from the true distribution within a larger population, further studies using a larger sample size need to be conducted. Nevertheless, the genetic information obtained here should facilitate genetic linkage studies of various hereditary diseases, especially in the Korean population.

\section{Abbreviations \\ Polymerase chain reaction; PCR Centi-morgans from the telomere of the $\mathrm{p}$ arm; $\mathrm{cM}$}

\section{References}

1) Reed PW, Davies JL, Copeman JB, Bennett ST, Palmer SM, Pritchard LE, Gough SC, Kawaguchi Y, Cordell HJ, Balfour KM, Jenkins SC, Powell EE, Vignal A and Todd JA : Chromosome-specific microsatellite sets for fluorescence-based, semi-automated genome mapping. Nat Genet 7 : 390-395 (1994)

2) Levitt RC, Kiser MB, Dragwa C, Jedlicka AE, Xu J, Meyers DA and Hudson JR: Fluorescence-based resource for semiautomated genomic analyses using microsatellite markers. Genomics 24:361-365 (1994)

3) Dubovsky J, Sheffield VC, Duyk GM and Weber JL: Sets of short tandem repeat polymorphisms for efficient linkage screening of the human genome. Hum Mol Genet $4: 449-452$ (1995)

4) Yuan B, Vaske D, Weber JL, Beck J and Sheffield VC: Improved set of short-tandem-repeat polymorphisms for screening the human genome. Am J Hum Genet 60 : 459-460 (1997)

5) Lee JK, Kim HT, Cho SM, Kim KH, Jin HJ, Ryu GM, Oh B, Park C, Kimm K, Jo SA, Jung SC, Kim S, In SM, Lee JE and Jo I: Characterization of 458 single nucleotide polymorphisms of disease candidate genes in the Korean population. J Hum Genet $48: 213-216$ (2003)

6) Yamane-Tanaka Y, Kogawa K, Tanaka T, Nakamura $Y$ and Isomura $M$ : Heterozygosities and allelic frequencies of 358 dinucleotide-repeat marker loci in the Japanese population. J Hum Genet 43:165-168 (1998)

7) Saha $\mathbf{N}$ and Tay JS: Origin of the Koreans: a population genetic study. Am J Phys Anthropol 88:27-36 (1992)

8) Nei M and Roychoudhury AK : Evolutionary relationships of human populations on a global scale. Mol Biol Evol 10 : 927-943 (1993)

9) Kim W, Shin DJ, You SA and Kim YJ : Y-specific DNA polymorphisms of the YAP element and the locus DYS19 in the Korean population. J Hum Genet 43 : 195-198 (1998)

10) Hammer MF and Horai S: Y chromosomal DNA variation and the peopling of Japan. Am J Hum Genet 56 : 951-962 (1995)

11) Okuda T, Fujioka Y, Kamide K, Kawano Y, Goto Y, Yoshimasa Y, Tomoike H, Iwai N, Hanai S and Miyata $\mathrm{T}$ : Verification of 525 coding SNPs in 179 hypertension candidate genes in the Japanese population: identification of 159 SNPs in 93 genes. J Hum Genet $47: 387-394(2002)$

12) Ikari K, Onda H, Furushima K, Maeda S, Harata S and Takeda J : Establishment of an optimized set of 406 microsatellite markers covering the whole genome for the Japanese population. J Hum Genet 46:207-210 (2001) 